\title{
Implicit Mann approximation with perturbations for nonexpansive semigroups in $\operatorname{CAT}(0)$ spaces
}

Xue-song $\mathrm{Li}^{1 *}$ and Tsz-leung Yip ${ }^{2}$

\section{"Correspondence:}

xuesongli78@hotmail.com

'Department of Mathematics,

Sichuan University, Chengdu,

Sichuan 610064, P.R. China

Full list of author information is

available at the end of the article

\begin{abstract}
In this paper, we study the convergence of implicit Mann iteration processes with bounded perturbations for approximating a common fixed point of nonexpansive semigroup in CAT(0) spaces. We obtain the $\triangle$-convergence results of implicit Mann iteration schemes with bounded perturbations for a family of nonexpansive mappings in CAT(0) spaces. Under certain and different conditions, we also get the strong convergence theorems of implicit Mann iteration schemes with bounded perturbations for nonexpansive semigroups in CAT(0) spaces. The results presented in this paper extend and enrich the existing literature.
\end{abstract}

MSC: $47 \mathrm{H} 05 ; 47 \mathrm{H} 10 ; 47 \mathrm{~J} 25$

Keywords: common fixed point; $\triangle$-convergence; nonexpansive semigroup; CAT(0) space; implicit approximation

\section{Introduction}

Let $(X, d)$ be a metric space and $K$ be a subset of $X$. A mapping $T: K \rightarrow X$ is said to be nonexpansive if $d(T x, T y) \leq d(x, y)$ for all $x, y \in K$. We denote the set of all nonnegative real numbers by $\mathbb{R}^{+}$and the set of all fixed points of $T$ by $F(T)$, i.e.,

$$
F(T)=\{x \in K: T x=x\} .
$$

For each $n \in \mathbb{N}$, let $T_{n}: K \rightarrow K$ be nonexpansive mappings and denote the common fixed points set of the family $\left\{T_{n}\right\}$ by $\bigcap_{n=1}^{\infty} F\left(T_{n}\right)$. A family of mappings $\left\{T_{n}\right\}$ is said to be uniformly asymptotically regular if, for any bounded subset $B$ of $K$,

$$
\lim _{n \rightarrow \infty} \sup _{z \in B} d\left(T_{n} z, T_{i}\left(T_{n} z\right)\right)=0
$$

for all $i \in \mathbb{N}$.

A nonexpansive semigroup is a family

$$
\Gamma:=\{T(t): t \geq 0\}
$$

of mappings $T(t)$ on $K$ such that

(1) $T(s+t) x=T(s)(T(t) x)$ for all $x \in K$ and $s, t \geq 0$;

o 2012 Li and Yip; licensee Springer. This is an Open Access article distributed under the terms of the Creative Commons Attribution License (http://creativecommons.org/licenses/by/2.0), which permits unrestricted use, distribution, and reproduction in any medium, provided the original work is properly cited. 
(2) $T(t): K \rightarrow K$ is nonexpansive for each $t \geq 0$;

(3) for each $x \in K$, the mapping $T(\cdot) x$ from $\mathbb{R}^{+}$to $K$ is continuous.

We denote by $F(\Gamma)$ the common fixed points set of nonexpansive semigroup $\Gamma$, i.e.,

$$
F(\Gamma)=\bigcap_{t \in \mathbb{R}^{+}} F(T(t))=\{x \in X: T(t) x=x \text { for each } t \geq 0\} .
$$

Note that, if $K$ is a nonempty, compact and convex subset of a Banach space, then $F(\Gamma)$ is nonempty (see [1-3]).

A geodesic from $x$ to $y$ in $X$ is a mapping $\Psi$ from a closed interval $[0, l] \subset \mathbb{R}$ to $X$ such that $\Psi(0)=x, \Psi(l)=y$ and $d\left(\Psi(t), \Psi\left(t^{\prime}\right)\right)=\left|t-t^{\prime}\right|$ for all $t, t^{\prime} \in[0, l]$. In particular, $\Psi$ is an isometry and $d(x, y)=l$. The image $\Theta$ of $\Psi$ is called a geodesic (or metric) segment joining $x$ and $y$. The space $(X, d)$ is said to be a geodesic space if any two points of $X$ are joined by a geodesic segment, and $X$ is said to be uniquely geodesic if there is exactly one geodesic joining $x$ and $y$ for any $x, y \in X$, which is denoted by $[x, y]$ and is called the segment joining $x$ and $y$. A subset $K$ of a geodesic space $X$ is said to be convex if for any $x, y \in K,[x, y] \subset K$.

A geodesic triangle $\triangle\left(x_{1}, x_{2}, x_{3}\right)$ in a geodesic metric space $(X, d)$ consists of three points $x_{1}, x_{2}, x_{3}$ in $X$ (the vertices of $\Delta$ ) and a geodesic segment between each pair of vertices (the edges of $\triangle$ ). A comparison triangle for the geodesic triangle $\Delta\left(x_{1}, x_{2}, x_{3}\right)$ in $(X, d)$ is a triangle $\bar{\triangle}\left(x_{1}, x_{2}, x_{3}\right)=\triangle\left(\bar{x}_{1}, \bar{x}_{2}, \bar{x}_{3}\right)$ in $\mathbb{R}^{2}$ such that $d_{\mathbb{R}^{2}}\left(\bar{x}_{i}, \bar{x}_{j}\right)=d\left(x_{i}, x_{j}\right)$ for all $i, j \in\{1,2,3\}$. It is known that such a triangle always exists (see [4]). A geodesic space is said to be a $\mathrm{CAT}(0)$ space if all geodesic triangles of appropriate size satisfy the following comparison axiom (CA):

(CA) Let $\triangle$ be a geodesic triangle in $(X, d)$ and let $\bar{\Delta} \subset \mathbb{R}^{2}$ be a comparison triangle for $\triangle$. Then $\Delta$ is said to satisfy the CAT(0) inequality if, for all $x, y \in \Delta$ and all comparison points $\bar{x}, \bar{y} \in \bar{\Delta}$,

$$
d(x, y) \leq d(\bar{x}, \bar{y})
$$

The complete CAT(0) spaces are often called Hadamard spaces (see [5]). For any $x, y \in X$, we denote by $\alpha x \oplus(1-\alpha) y$ the unique point $z \in[x, y]$ which satisfies

$$
d(x, \alpha x \oplus(1-\alpha) y)=(1-\alpha) d(x, y) \quad \text { and } \quad d(y, \alpha x \oplus(1-\alpha) y)=\alpha d(x, y) .
$$

It is known that if $(X, d)$ is a $\operatorname{CAT}(0)$ space and $x, y \in X$, then for any $\beta \in[0,1]$, there exists a unique point $\beta x \oplus(1-\beta) y \in[x, y]$. For any $z \in X$, the following inequality holds:

$$
d(z, \beta x \oplus(1-\beta) y) \leq \beta d(z, x)+(1-\beta) d(z, y),
$$

where $\beta x \oplus(1-\beta) y \in[x, y]$ (for metric spaces of hyperbolic type, see [6]).

Recently, Cho et al. [7] studied the strong convergence of an explicit Mann iteration sequence $\left\{z_{n}\right\}$ for approximating a common fixed point of $\Gamma$ in a CAT(0) space, where $\left\{z_{n}\right\}$ is generated by the following iterative scheme for a nonexpansive semigroup $\Gamma=\{T(t)$ : $\left.t \in \mathbb{R}^{+}\right\}$:

$$
z_{0} \in K, \quad z_{n}=\alpha z_{n-1} \oplus(1-\alpha) T\left(t_{n}\right) z_{n-1}, \quad \forall n \geq 1,
$$


where $\alpha \in(0,1)$ and $\left\{t_{n}\right\} \subset \mathbb{R}^{+}$. The existence of fixed points, an invariant approximation and convergence theorems for several mappings in CAT(0) spaces have been studied by many authors (see [8-19]).

On the other hand, Thong [20] considered an implicit Mann iteration process for a nonexpansive semigroup $\Gamma=\left\{T(t): t \in \mathbb{R}^{+}\right\}$on a closed convex subset $C$ of a Banach space, as follows:

$$
x_{0} \in C, \quad x_{n}=\alpha_{n} x_{n-1}+\left(1-\alpha_{n}\right) T\left(t_{n}\right) x_{n}, \quad n \geq 1 .
$$

Under different conditions, Thong [20] proved the weak convergence and strong convergence results of implicit Mann iteration scheme (1.1) for nonexpansive semigroups in certain Banach spaces. In the last twenty years, many authors have studied the convergence of implicit iteration sequences for nonexpansive mappings, nonexpansive semigroups and pseudocontractive semigroups in Banach spaces (see [21-24] and the references therein). Readers may consult $[11,25,26]$ for the convergence of Ishikawa iteration sequences for nonexpansive mappings and nonexpansive semigroups in certain Banach spaces. In the literature of approximating convergence for nonexpansive mappings and nonexpansive semigroups in CAT(0) spaces, explicit iteration schemes are very abundant but implicit iteration process remains unaddressed. Therefore, it is of interest to investigate the convergence of implicit Mann type process with perturbations for nonexpansive semigroups in $\operatorname{CAT}(0)$ spaces.

Motivated and inspired by the work mentioned above, we consider the following implicit Mann iteration scheme with perturbations $\left\{u_{n}\right\}$ for a family of nonexpansive mappings in a CAT(0) space:

$$
x_{0} \in K, \quad x_{n}=\alpha_{n} x_{n-1} \oplus\left(1-\alpha_{n}\right)\left(\left(1-\theta_{n}\right) T_{n} x_{n} \oplus \theta_{n} u_{n}\right), \quad \forall n \geq 1,
$$

where $\left\{\alpha_{n}\right\} \subset(0,1]$ and $\left\{\theta_{n}\right\} \subset[0,1]$ are given sequences of real numbers, $\left\{u_{n}\right\}$ is a bounded sequence in $K$. We prove that $\left\{x_{n}\right\}$ generated by (1.2) is $\Delta$-convergent to some point in $\bigcap_{n=1}^{\infty} F\left(T_{n}\right)$ under appropriate conditions. We also consider the following implicit Mann iteration process with perturbations $\left\{u_{n}\right\}$ for a nonexpansive semigroup $\Gamma=\{T(t): t \geq 0\}$ in a $\operatorname{CAT}(0)$ space:

$$
x_{0} \in K, \quad x_{n}=\alpha_{n} x_{n-1} \oplus\left(1-\alpha_{n}\right)\left(\left(1-\theta_{n}\right) T\left(t_{n}\right) x_{n} \oplus \theta_{n} u_{n}\right), \quad \forall n \geq 1,
$$

where $\left\{\alpha_{n}\right\} \subset(0,1]$ and $\left\{\theta_{n}\right\} \subset[0,1]$ are given sequences of real numbers, $\left\{u_{n}\right\}$ is a bounded sequence in $K$. Under various and appropriate conditions, we obtain that $\left\{x_{n}\right\}$ generated by (1.3) converges strongly to a common fixed point of $\Gamma$. We extend the strong convergence result in [20] and establish the $\triangle$-convergence results of implicit Mann type approximation for nonexpansive semigroups in $\mathrm{CAT}(0)$ spaces.

\section{Definitions and lemmas}

Let $\left\{x_{n}\right\}$ be a bounded sequence in a $\operatorname{CAT}(0)$ space $(X, d)$. For any $x \in X$, denote

$$
r\left(x,\left\{x_{n}\right\}\right)=\limsup _{n \rightarrow \infty} d\left(x, x_{n}\right) .
$$

(i) $r\left(\left\{x_{n}\right\}\right)=\inf \left\{r\left(x, x_{n}\right): x \in X\right\}$ is called the asymptotic radius of $\left\{x_{n}\right\}$; 
(ii) $r_{K}\left(\left\{x_{n}\right\}\right)=\inf \left\{r\left(x, x_{n}\right): x \in K\right\}$ is called the asymptotic radius of $\left\{x_{n}\right\}$ with respect to $K$;

(iii) the set $A\left(\left\{x_{n}\right\}\right)=\left\{x \in X: r\left(x,\left\{x_{n}\right\}\right)=r\left(\left\{x_{n}\right\}\right)\right\}$ is called the asymptotic center of $\left\{x_{n}\right\}$;

(iv) the set $A_{K}\left(\left\{x_{n}\right\}\right)=\left\{x \in K: r\left(x,\left\{x_{n}\right\}\right)=r_{K}\left(\left\{x_{n}\right\}\right)\right\}$ is called the asymptotic center of $\left\{x_{n}\right\}$ with respect to $K$.

Definition 2.1 $[13,27]$ A sequence $\left\{x_{n}\right\}$ in a CAT $(0)$ space $X$ is said to be $\triangle$-convergent to a point $x$ in $X$, if $x$ is the unique asymptotic center of $\left\{x_{n_{j}}\right\}$ for all subsequences $\left\{x_{n_{j}}\right\} \subseteq\left\{x_{n}\right\}$. In this case, we write $\Delta-\lim _{n \rightarrow \infty} x_{n}=x$ and $x$ is called the $\Delta$-limit of $\left\{x_{n}\right\}$.

For the sake of convenience, we restate the following lemmas that shall be used.

Lemma $2.1[11]$ Let $(X, d)$ be a CAT(0) space. Then,

$$
d((1-t) x \oplus t y, z) \leq(1-t) d(x, z)+t d(y, z)
$$

for all $x, y, z \in X$ and $t \in[0,1]$.

Lemma 2.2 [11] Let $(X, d)$ be a CAT(0) space. Then,

$$
[d((1-t) x \oplus t y, z)]^{2} \leq(1-t)[d(x, z)]^{2}+t[d(y, z)]^{2}-t(1-t)[d(x, y)]^{2}
$$

for all $x, y, z \in X$ and $t \in[0,1]$.

Lemma 2.3 [11] Let $K$ be a closed convex subset of a complete CAT(0) space and $T$ : $K \rightarrow K$ be a nonexpansive mapping. Suppose that $\left\{x_{n}\right\}$ is a bounded sequence in $K$ such that $\lim _{n \rightarrow \infty} d\left(x_{n}, T x_{n}\right)=0$ and $\left\{d\left(x_{n}, p\right)\right\}$ converges for all $p \in F(T)$. Then, $\omega_{w}\left(x_{n}\right)=$ $\bigcup A\left(\left\{x_{n_{j}}\right\}\right) \subset F(T)$, where the union is taken over all subsequences $\left\{x_{n_{j}}\right\}$ of $\left\{x_{n}\right\}$. Moreover, $\omega_{w}\left(x_{n}\right)$ consists of exactly one point.

Lemma 2.4 [7] Let $\left\{z_{n}\right\}$ and $\left\{w_{n}\right\}$ be bounded sequences in a CAT(0) space X. Let $\left\{\alpha_{n}\right\}$ be a sequence in $[0,1]$ such that $0<\liminf _{n \rightarrow \infty} \alpha_{n} \leq \limsup _{n \rightarrow \infty} \alpha_{n}<1$. Define $z_{n}=\alpha_{n} z_{n-1} \oplus$ $\left(1-\alpha_{n}\right) w_{n}$ for all $n \in \mathbb{N}$ and suppose that

$$
\limsup _{n \rightarrow \infty}\left[d\left(w_{n+1}, w_{n}\right)-d\left(z_{n+1}, z_{n}\right)\right] \leq 0
$$

Then $\lim _{n \rightarrow \infty} d\left(w_{n}, z_{n}\right)=0$.

Lemma 2.5 [26] Let $\left\{a_{n}\right\},\left\{\alpha_{n}\right\}$ and $\left\{\beta_{n}\right\}$ be sequences of nonnegative real numbers such that

$$
a_{n+1} \leq\left(1+\alpha_{n}\right) a_{n}+\beta_{n}, \quad n \geq n_{0},
$$

where $n_{0}$ is some nonnegative integer. If $\sum \alpha_{n}<+\infty$ and $\sum \beta_{n}<+\infty$, then $\lim _{n \rightarrow \infty} a_{n}$ exists. 


\section{Main results}

To focus on the convergence results of this present paper, it is necessary to show that the sequences generated by implicit Mann iteration processes (1.2) and (1.3) are well defined.

Lemma 3.1 Let $K$ be a nonempty, closed and convex subset of a complete $C A T(0)$ space $X$ and $T_{n}: K \rightarrow K$ be nonexpansive mappings. Suppose that $\left\{u_{n}\right\}$ is a bounded sequence in $K,\left\{\alpha_{n}\right\} \subset(0,1]$ and $\left\{\theta_{n}\right\} \subset[0,1]$ are given parameter sequences. Then the sequence $\left\{x_{n}\right\}$ generated by implicit Mann iteration process (1.2) is well defined.

Proof For each $n \in \mathbb{N}$ and any given $u, v \in K$, define a mapping $S_{n}: K \rightarrow K$ by

$$
S_{n} x:=\alpha_{n} u \oplus\left(1-\alpha_{n}\right)\left(\left(1-\theta_{n}\right) T_{n} x \oplus \theta_{n} v\right), \quad \forall n \geq 1 .
$$

It can be verified that for each fixed $n \in \mathbb{N}, S_{n}$ is a contractive mapping. Indeed, if setting $p_{n}=\left(1-\theta_{n}\right) T_{n} x \oplus \theta_{n} v$ and $q_{n}=\left(1-\theta_{n}\right) T_{n} y \oplus \theta_{n} v$, then we have $S_{n} x=\alpha_{n} u \oplus\left(1-\alpha_{n}\right) p_{n}$ and $S_{n} y=\alpha_{n} u \oplus\left(1-\alpha_{n}\right) q_{n}$. It follows from Lemmas 2.2 and 2.1 that

$$
\begin{aligned}
{\left[d\left(S_{n} x, S_{n} y\right)\right]^{2}=} & {\left[d\left(S_{n} x, \alpha_{n} u \oplus\left(1-\alpha_{n}\right) q_{n}\right)\right]^{2} } \\
\leq & \left(1-\alpha_{n}\right)\left[d\left(S_{n} x, q_{n}\right)\right]^{2}+\alpha_{n}\left[d\left(S_{n} x, u\right)\right]^{2}-\alpha_{n}\left(1-\alpha_{n}\right)\left[d\left(u, q_{n}\right)\right]^{2} \\
\leq & \left(1-\alpha_{n}\right)\left\{\left(1-\alpha_{n}\right)\left[d\left(p_{n}, q_{n}\right)\right]^{2}+\alpha_{n}\left[d\left(u, q_{n}\right)\right]^{2}-\alpha_{n}\left(1-\alpha_{n}\right)\left[d\left(u, p_{n}\right)\right]^{2}\right\} \\
& +\alpha_{n}\left(1-\alpha_{n}\right)^{2}\left[d\left(p_{n}, u\right)\right]^{2}-\alpha_{n}\left(1-\alpha_{n}\right)\left[d\left(u, q_{n}\right)\right]^{2} \\
= & \left(1-\alpha_{n}\right)^{2}\left[d\left(p_{n}, q_{n}\right)\right]^{2} .
\end{aligned}
$$

Consequently, we have that $d\left(S_{n} x, S_{n} y\right) \leq\left(1-\alpha_{n}\right) d\left(p_{n}, q_{n}\right)$ and $d\left(p_{n}, q_{n}\right) \leq\left(1-\theta_{n}\right) d\left(T_{n} x\right.$, $\left.T_{n} y\right) \leq\left(1-\theta_{n}\right) d(x, y)$. Thus,

$$
d\left(S_{n} x, S_{n} y\right) \leq\left(1-\alpha_{n}\right)\left(1-\theta_{n}\right) d(x, y)
$$

which shows that for each $n \in \mathbb{N}, S_{n}$ is a contractive mapping. By induction, Banach's fixed theorem yields that the sequence $\left\{x_{n}\right\}$ generated by $(1.2)$ is well defined. This completes the proof.

We need the following lemma for our main results. The analogs of [7, Lemma 3.1] and [28, Lemma 2.2] are given below. We sketch the proof here for the convenience of the reader.

Lemma 3.2 Let $K$ be a nonempty, closed and convex subset of a complete CAT(0) space $X$, $\left\{u_{n}\right\}$ be a bounded sequence in $K$ and $T_{n}: K \rightarrow K$ be nonexpansive mappings. Let $\left\{\alpha_{n}\right\} \subset$ $(0,1]$ and $\left\{\theta_{n}\right\} \subset[0,1]$ be given sequences such that $0<\liminf _{n \rightarrow \infty} \alpha_{n} \leq \lim _{\sup _{n \rightarrow \infty}} \alpha_{n}<1$. Suppose that $\left\{x_{n}\right\}$ generated by (1.2) is bounded (or, equivalently, $\left\{T_{n} x_{n}\right\}$ is bounded) and either

$$
\lim _{n \rightarrow \infty} d\left(T_{n+1} x_{n}, T_{n} x_{n}\right)=0 \quad \text { or } \quad \lim _{n \rightarrow \infty} d\left(T_{n+1} x_{n+1}, T_{n} x_{n+1}\right)=0
$$

holds. If $\lim _{n \rightarrow \infty} \theta_{n}=0$, then $\lim _{n \rightarrow \infty} d\left(T_{n} x_{n}, x_{n}\right)=0$. 
Proof First, we show the equivalence between the boundedness of $\left\{x_{n}\right\}$ and the boundedness of $\left\{T_{n} x_{n}\right\}$. If $\left\{x_{n}\right\}$ is bounded, then set

$$
M_{1}=\sup \left\{d\left(x_{n}, x\right): n \in \mathbb{N}\right\}<+\infty, \quad M_{2}=\sup \left\{d\left(u_{n}, x\right): n \in \mathbb{N}\right\}<+\infty
$$

for some given point $x \in X$ and $\alpha=\liminf _{n \rightarrow \infty} \alpha_{n}>0, \beta=\limsup _{n \rightarrow \infty} \alpha_{n}<1$. Setting $0<$ $a<\alpha \leq \beta<b<1$, we know that there exists $n_{1} \in \mathbb{N}$ such that for all $n \geq n_{1}$,

$$
\theta_{n} \leq 2 / 3, \quad 0<a<\alpha_{n}<b<1 .
$$

It follows from Lemma 2.1 that

$$
\begin{aligned}
d\left(T_{n} x_{n}, x\right) & \leq d\left(T_{n} x_{n}, x_{n}\right)+d\left(x_{n}, x\right) \\
& =d\left(T_{n} x_{n}, \alpha_{n} x_{n-1} \oplus\left(1-\alpha_{n}\right)\left(\left(1-\theta_{n}\right) T_{n} x_{n} \oplus \theta_{n} u_{n}\right)\right)+d\left(x_{n}, x\right) \\
& \leq \alpha_{n} d\left(T_{n} x_{n}, x_{n-1}\right)+\left(1-\alpha_{n}\right) d\left(T_{n} x_{n},\left(1-\theta_{n}\right) T_{n} x_{n} \oplus \theta_{n} u_{n}\right)+d\left(x_{n}, x\right) \\
& \leq \alpha_{n} d\left(T_{n} x_{n}, x_{n-1}\right)+\left(1-\alpha_{n}\right) \theta_{n} d\left(T_{n} x_{n}, u_{n}\right)+d\left(x_{n}, x\right) \\
& \leq \alpha_{n} d\left(T_{n} x_{n}, x\right)+\alpha_{n} d\left(x_{n-1}, x\right)+\left(1-\alpha_{n}\right) \theta_{n}\left[d\left(T_{n} x_{n}, x\right)+d\left(u_{n}, x\right)\right]+d\left(x_{n}, x\right) \\
& \leq\left[\alpha_{n}+\left(1-\alpha_{n}\right) \theta_{n}\right] d\left(T_{n} x_{n}, x\right)+d\left(x_{n-1}, x\right)+d\left(u_{n}, x\right)+d\left(x_{n}, x\right) .
\end{aligned}
$$

Hence, for all $n \geq n_{1}$, from (3.1) we have

$$
\begin{aligned}
d\left(T_{n} x_{n}, x\right) & \leq \frac{1}{\left(1-\alpha_{n}\right)\left(1-\theta_{n}\right)}\left[d\left(x_{n-1}, x\right)+d\left(u_{n}, x\right)+d\left(x_{n}, x\right)\right] \\
& \leq\left(6 M_{1}+3 M_{2}\right) /(1-b),
\end{aligned}
$$

which means that $\left\{T_{n} x_{n}\right\}$ is bounded.

Conversely, if $\left\{T_{n} x_{n}\right\}$ is bounded, then set

$$
Q_{1}=\sup \left\{d\left(T_{n} x_{n}, x\right): n \in \mathbb{N}\right\}<+\infty \quad \text { and } \quad M_{2}=\sup \left\{d\left(u_{n}, x\right): n \in \mathbb{N}\right\}<+\infty
$$

for some given point $x \in X$. Denote $Q=\max \left\{Q_{1}, M_{2}\right\}$. From Lemma 2.1, we have

$$
\begin{aligned}
d\left(x_{n}, x\right) & =d\left(\alpha_{n} x_{n-1} \oplus\left(1-\alpha_{n}\right)\left(\left(1-\theta_{n}\right) T_{n} x_{n} \oplus \theta_{n} u_{n}\right), x\right) \\
& \leq \alpha_{n} d\left(x_{n-1}, x\right)+\left(1-\alpha_{n}\right)\left(1-\theta_{n}\right) d\left(T_{n} x_{n}, x\right)+\left(1-\alpha_{n}\right) \theta_{n} d\left(u_{n}, x\right) \\
& \leq \alpha_{n} d\left(x_{n-1}, x\right)+\left(1-\alpha_{n}\right) Q \\
& \leq \max \left\{d\left(x_{n-1}, x\right), Q\right\} .
\end{aligned}
$$

By induction, we know that $d\left(x_{n}, x\right) \leq \max \left\{d\left(x_{1}, x\right), Q\right\}$, which shows that $\left\{x_{n}\right\}$ is bounded.

Then, we prove Lemma 3.2. If $\lim _{n \rightarrow \infty} d\left(T_{n+1} x_{n}, T_{n} x_{n}\right)=0$, then we have

$$
\begin{aligned}
& \limsup _{n \rightarrow \infty}\left[d\left(\left(1-\theta_{n+1}\right) T_{n+1} x_{n+1} \oplus \theta_{n+1} u_{n+1},\left(1-\theta_{n}\right) T_{n} x_{n} \oplus \theta_{n} u_{n}\right)-d\left(x_{n+1}, x_{n}\right)\right] \\
& \quad \leq \limsup _{n \rightarrow \infty}\left[d\left(\left(1-\theta_{n+1}\right) T_{n+1} x_{n+1} \oplus \theta_{n+1} u_{n+1}, T_{n+1} x_{n+1}\right)+d\left(T_{n+1} x_{n+1}, T_{n+1} x_{n}\right)\right.
\end{aligned}
$$




$$
\begin{aligned}
& \left.+d\left(T_{n+1} x_{n}, T_{n} x_{n}\right)+d\left(T_{n} x_{n},\left(1-\theta_{n}\right) T_{n} x_{n} \oplus \theta_{n} T_{n} x_{n+1}\right)-d\left(x_{n+1}, x_{n}\right)\right] \\
\leq & \limsup _{n \rightarrow \infty}\left[\theta_{n+1} d\left(u_{n+1}, T_{n+1} x_{n+1}\right)+\theta_{n} d\left(T_{n} x_{n}, T_{n} x_{n+1}\right)\right] \\
\leq & \limsup _{n \rightarrow \infty}\left[\theta_{n+1} d\left(u_{n+1}, x\right)+\theta_{n+1} d\left(T_{n+1} x_{n+1}, x\right)+\theta_{n} d\left(x_{n}, x\right)+\theta_{n} d\left(x_{n+1}, x\right)\right] \\
\leq & \limsup _{n \rightarrow \infty}\left(\theta_{n+1}+\theta_{n}\right)\left[d\left(u_{n+1}, x\right)+d\left(T_{n+1} x_{n+1}, x\right)+d\left(x_{n+1}, x\right)+d\left(x_{n}, x\right)\right] \\
\leq & \limsup _{n \rightarrow \infty}\left(M_{2}+Q_{1}+2 M_{1}\right)\left(\theta_{n+1}+\theta_{n}\right)=0 .
\end{aligned}
$$

Similarly, if $\lim _{n \rightarrow \infty} d\left(T_{n+1} x_{n+1}, T_{n} x_{n+1}\right)=0$, then from inequality (3.2) we have

$$
\begin{aligned}
& \limsup _{n \rightarrow \infty}\left[d\left(\left(1-\theta_{n+1}\right) T_{n+1} x_{n+1} \oplus \theta_{n+1} u_{n+1},\left(1-\theta_{n}\right) T_{n} x_{n} \oplus \theta_{n} u_{n}\right)-d\left(x_{n+1}, x_{n}\right)\right] \\
& \leq \limsup _{n \rightarrow \infty}\left[d\left(\left(1-\theta_{n+1}\right) T_{n+1} x_{n+1} \oplus \theta_{n+1} u_{n+1}, T_{n+1} x_{n+1}\right)+d\left(T_{n+1} x_{n+1}, T_{n} x_{n+1}\right)\right. \\
& \left.\quad+d\left(T_{n} x_{n+1}, T_{n} x_{n}\right)+d\left(T_{n} x_{n},\left(1-\theta_{n}\right) T_{n} x_{n} \oplus \theta_{n} T_{n} x_{n+1}\right)-d\left(x_{n+1}, x_{n}\right)\right] \\
& \quad \limsup _{n \rightarrow \infty}\left[\theta_{n+1} d\left(u_{n+1}, T_{n+1} x_{n+1}\right)+\theta_{n} d\left(T_{n} x_{n}, T_{n} x_{n+1}\right)\right]=0 .
\end{aligned}
$$

It follows from Lemma 2.4 that $\lim _{n \rightarrow \infty} d\left(\left(1-\theta_{n}\right) T_{n} x_{n} \oplus \theta_{n} u_{n}, x_{n}\right)=0$. Note that

$$
\begin{aligned}
\lim _{n \rightarrow \infty} d\left(x_{n}, T_{n} x_{n}\right) & \leq \lim _{n \rightarrow \infty}\left[d\left(x_{n},\left(1-\theta_{n}\right) T_{n} x_{n} \oplus \theta_{n} u_{n}\right)+d\left(\left(1-\theta_{n}\right) T_{n} x_{n} \oplus \theta_{n} u_{n}, T_{n} x_{n}\right)\right] \\
& \leq \lim _{n \rightarrow \infty}\left[d\left(\left(1-\theta_{n}\right) T_{n} x_{n} \oplus \theta_{n} u_{n}, x_{n}\right)+\theta_{n} d\left(u_{n}, T_{n} x_{n}\right)\right] \\
& \leq \lim _{n \rightarrow \infty}\left[d\left(\left(1-\theta_{n}\right) T_{n} x_{n} \oplus \theta_{n} u_{n}, x_{n}\right)+\theta_{n}\left(d\left(u_{n}, x\right)+d\left(T_{n} x_{n}, x\right)\right)\right] \\
& \leq \lim _{n \rightarrow \infty}\left[d\left(\left(1-\theta_{n}\right) T_{n} x_{n} \oplus \theta_{n} u_{n}, x_{n}\right)+\left(M_{2}+Q_{1}\right) \theta_{n}\right]=0 .
\end{aligned}
$$

We have that $\lim _{n \rightarrow \infty} d\left(T_{n} x_{n}, x_{n}\right)=0$. This completes the proof.

As a direct consequence of Lemma 3.2, the following lemma is immediate.

Lemma 3.3 Let $K$ be a nonempty, closed and convex subset of a complete $C A T(0)$ space $X$, $\left\{u_{n}\right\}$ be a bounded sequence in $K$ and $T_{n}: K \rightarrow K$ be nonexpansive mappings. Let $\left\{\alpha_{n}\right\} \subset$ $(0,1]$ and $\left\{\theta_{n}\right\} \subset[0,1]$ be given sequences such that $0<\liminf _{n \rightarrow \infty} \alpha_{n} \leq \limsup _{n \rightarrow \infty} \alpha_{n}<1$. Suppose that $\left\{x_{n}\right\}$ generated by (1.2) is bounded (or, equivalently, $\left\{T_{n} x_{n}\right\}$ is bounded) and

$$
\lim _{n \rightarrow \infty} \sup _{x \in K} d\left(T_{n+1} x, T_{n} x\right)=0
$$

holds. If $\lim _{n \rightarrow \infty} \theta_{n}=0$, then $\lim _{n \rightarrow \infty} d\left(T_{n} x_{n}, x_{n}\right)=0$.

We now present our main results. The following theorem discusses the $\triangle$-convergence of implicit Mann iteration sequence (1.2) with perturbations for a family of nonexpansive mappings in $\mathrm{CAT}(0)$ spaces.

Theorem 3.1 Let $K$ be a nonempty, closed and convex subset of a complete CAT(O) space $X$, and $T_{n}: K \rightarrow K$ be uniformly asymptotically regular and nonexpansive mappings such that $\bigcap_{n=1}^{\infty} F\left(T_{n}\right) \neq \emptyset$. Let $\left\{u_{n}\right\}$ be a bounded sequence in $K,\left\{\alpha_{n}\right\} \subset(0,1]$ and $\left\{\theta_{n}\right\} \subset[0,1]$ be 
given sequences such that $0<\liminf _{n \rightarrow \infty} \alpha_{n} \leq \lim \sup _{n \rightarrow \infty} \alpha_{n}<1$. Then the sequence $\left\{x_{n}\right\}$ generated by (1.2) is well defined. Suppose that $\sum_{n=1}^{\infty} \theta_{n}<+\infty$ and either

$$
\lim _{n \rightarrow \infty} d\left(T_{n+1} x_{n}, T_{n} x_{n}\right)=0 \quad \text { or } \quad \lim _{n \rightarrow \infty} d\left(T_{n+1} x_{n+1}, T_{n} x_{n+1}\right)=0
$$

holds. Then $\left\{x_{n}\right\} \triangle$-converges to some point in $\bigcap_{n=1}^{\infty} F\left(T_{n}\right)$.

Proof By Lemma 3.1, we know that the sequence $\left\{x_{n}\right\}$ generated by (1.2) is well defined. For any $p \in \bigcap_{n=1}^{\infty} F\left(T_{n}\right)$, from (1.2) and Lemma 2.1, we have

$$
\begin{aligned}
d\left(x_{n}, p\right) & =d\left(\alpha_{n} x_{n-1} \oplus\left(1-\alpha_{n}\right)\left(\left(1-\theta_{n}\right) T_{n} x_{n} \oplus \theta_{n} u_{n}\right), p\right) \\
& \leq \alpha_{n} d\left(x_{n-1}, p\right)+\left(1-\alpha_{n}\right)\left(\left(1-\theta_{n}\right) d\left(T_{n} x_{n}, p\right)+\theta_{n} d\left(u_{n}, p\right)\right) \\
& \leq \alpha_{n} d\left(x_{n-1}, p\right)+\left(1-\alpha_{n}\right)\left(1-\theta_{n}\right) d\left(x_{n}, p\right)+\left(1-\alpha_{n}\right) \theta_{n} d\left(u_{n}, p\right) .
\end{aligned}
$$

Since $\alpha_{n} \leq 1-\left(1-\alpha_{n}\right)\left(1-\theta_{n}\right)$, it follows from (3.1) that for all $n \geq n_{1}$,

$$
d\left(x_{n}, p\right) \leq d\left(x_{n-1}, p\right)+\frac{\left(1-\alpha_{n}\right) \theta_{n}}{1-\left(1-\alpha_{n}\right)\left(1-\theta_{n}\right)} d\left(u_{n}, p\right) \leq d\left(x_{n-1}, p\right)+\frac{1}{a} \theta_{n} d\left(u_{n}, p\right) .
$$

Since $\sum_{n=1}^{\infty} \theta_{n}<+\infty$ and $\left\{u_{n}\right\}$ is bounded, Lemma 2.5 yields that $\left\{d\left(x_{n}, p\right)\right\}$ converges and thus $\left\{x_{n}\right\}$ is bounded.

Applying Lemma 3.2, we have $\lim _{n \rightarrow \infty} d\left(x_{n}, T_{n} x_{n}\right)=0$. We prove that for each $i \in \mathbb{N}$,

$$
\lim _{n \rightarrow \infty} d\left(x_{n}, T_{i} x_{n}\right)=0 .
$$

Because the family of nonexpansive mappings $\left\{T_{i}\right\}$ is uniformly asymptotically regular, we have

$$
\begin{aligned}
d\left(x_{n}, T_{i} x_{n}\right) & \leq d\left(x_{n}, T_{n} x_{n}\right)+d\left(T_{n} x_{n}, T_{i}\left(T_{n} x_{n}\right)\right)+d\left(T_{i}\left(T_{n} x_{n}\right), T_{i} x_{n}\right) \\
& \leq 2 d\left(x_{n}, T_{n} x_{n}\right)+\sup _{z \in\left\{x_{n}\right\}} d\left(T_{n} z, T_{i}\left(T_{n} z\right)\right) \rightarrow 0 .
\end{aligned}
$$

Since $\left\{d\left(x_{n}, p\right)\right\}$ converges for any $p \in \bigcap_{n=1}^{\infty} F\left(T_{n}\right)$, an application of Lemma 2.3 yields that $\omega_{w}\left(x_{n}\right)$ consists of exactly one point and is contained in $F\left(T_{i}\right)$, for all $i \in \mathbb{N}$. This shows that $\left\{x_{n}\right\} \triangle$-converges to some point in $\bigcap_{n=1}^{\infty} F\left(T_{n}\right)$. This completes the proof.

By Lemma 3.3 and Theorem 3.1, the following theorem holds trivially.

Theorem 3.2 Let $K$ be a nonempty, closed and convex subset of a complete CAT(0) space $X$, and $T_{n}: K \rightarrow K$ be uniformly asymptotically regular and nonexpansive mappings such that $\bigcap_{n=1}^{\infty} F\left(T_{n}\right) \neq \emptyset$. Let $\left\{u_{n}\right\}$ be a bounded sequence in $K,\left\{\alpha_{n}\right\} \subset(0,1]$ and $\left\{\theta_{n}\right\} \subset[0,1]$ be given sequences such that $0<\liminf _{n \rightarrow \infty} \alpha_{n} \leq \lim \sup _{n \rightarrow \infty} \alpha_{n}<1$. Then the sequence $\left\{x_{n}\right\}$ generated by (1.2) is well defined. Suppose that $\sum_{n=1}^{\infty} \theta_{n}<+\infty$ and

$$
\lim _{n \rightarrow \infty} \sup _{x \in K} d\left(T_{n+1} x, T_{n} x\right)=0
$$

holds. Then $\left\{x_{n}\right\} \triangle$-converges to some point in $\bigcap_{n=1}^{\infty} F\left(T_{n}\right)$. 
Finally, we study the strong convergence of implicit Mann iteration sequence (1.3) with perturbations for a nonexpansive semigroup in $\mathrm{CAT}(0)$ spaces, under various and appropriate conditions.

Theorem 3.3 Let $K$ be a compact and convex subset of a complete CAT( 0$)$ space $X$, and $\Gamma=\left\{T(t): t \in \mathbb{R}^{+}\right\}$be a nonexpansive semigroup on $K$. Let $\left\{u_{n}\right\}$ be a bounded sequence in $K,\left\{\alpha_{n}\right\} \subset(0,1]$ and $\left\{\theta_{n}\right\} \subset[0,1]$ be given sequences such that $0<\liminf _{n \rightarrow \infty} \alpha_{n} \leq$ $\limsup _{n \rightarrow \infty} \alpha_{n}<1$. Then the sequence $\left\{x_{n}\right\}$ generated by implicit scheme (1.3) is well defined. Suppose that $\left\{t_{n}\right\}$ is a sequence in $\mathbb{R}^{+}$such that

$$
\liminf _{n \rightarrow \infty} t_{n}<\limsup _{n \rightarrow \infty} t_{n} \text { and } \lim _{n \rightarrow \infty}\left(t_{n+1}-t_{n}\right)=0 .
$$

If $\sum_{n=1}^{\infty} \theta_{n}<+\infty$, then $\left\{x_{n}\right\}$ converges strongly to some point in $F(\Gamma)$.

Proof Following the proof details of the main result of [2], we know that $F(\Gamma)$ in complete $\mathrm{CAT}(0)$ spaces is nonempty (see $[2,7])$. From Lemma 3.1 , it is easy to see that the sequence $\left\{x_{n}\right\}$ generated by $(1.3)$ is well defined. We show that

$$
\lim _{n \rightarrow \infty} \sup _{x \in K} d\left(T\left(t_{n}\right) x, T\left(t_{n-1}\right) x\right)=0 .
$$

Assume for the contrary that (3.4) does not hold. There exist a subsequence $\left\{t_{n_{k}}\right\} \subset\left\{t_{n}\right\}$, a sequence $\left\{y_{k}\right\} \subset K$ and an $\eta>0$ such that for all $k \in \mathbb{N}$,

$$
d\left(T\left(t_{n_{k}}\right) y_{k}, T\left(t_{n_{k}-1}\right) y_{k}\right) \geq \eta
$$

Since $K$ is compact, there exists a convergent subsequence of $\left\{y_{k}\right\}$. Without loss of generality, we assume that $y_{k} \rightarrow y$ as $k \rightarrow \infty$. Obviously, $y \in K$ and so

$$
\begin{aligned}
0< & \eta \\
\leq & \limsup _{k \rightarrow \infty} d\left(T\left(t_{n_{k}}\right) y_{k}, T\left(t_{n_{k}-1}\right) y_{k}\right) \\
\leq & \limsup _{k \rightarrow \infty} d\left(T\left(\left|t_{n_{k}}-t_{n_{k}-1}\right|\right) y_{k}, T(0) y_{k}\right) \\
\leq & \limsup _{k \rightarrow \infty}\left[d\left(T\left(\left|t_{n_{k}}-t_{n_{k}-1}\right|\right) y_{k}, T\left(\left|t_{n_{k}}-t_{n_{k}-1}\right|\right) y\right)\right. \\
& \left.\quad+d\left(T\left(\left|t_{n_{k}}-t_{n_{k}-1}\right|\right) y, T(0) y\right)+d\left(T(0) y, T(0) y_{k}\right)\right] \\
\leq & \limsup _{k \rightarrow \infty}\left[2 d\left(y_{k}, y\right)+d\left(T\left(\left|t_{n_{k}}-t_{n_{k}-1}\right|\right) y, T(0) y\right)\right]=0,
\end{aligned}
$$

which is a contradiction. Formula (3.4) follows readily. By Lemma 3.3, we have

$$
\lim _{n \rightarrow \infty} d\left(T\left(t_{n}\right) x_{n}, x_{n}\right)=0 .
$$

Following the proof of [7, Theorem 3.5], we can show that there exists a subsequence $\left\{x_{n_{j}}\right\}$ convergent to $x^{*}$, where $x^{*}$ is a common fixed point of $\left\{T(t): t \in \mathbb{R}^{+}\right\}$. Since $x^{*}$ is a cluster of $\left\{x_{n}\right\}$, we have $\liminf _{n \rightarrow \infty} d\left(x_{n}, x^{*}\right)=0$. It follows from (1.3) and (3.3) that $\lim _{n \rightarrow \infty} d\left(x_{n}, x^{*}\right)$ exists. Hence, $\lim _{n \rightarrow \infty} d\left(x_{n}, x^{*}\right)=0$, which completes the proof. 
Remark 3.1 The proofs of Theorems 3.1 and 3.3 are respectively similar to [7, Theorems 3.4 and 3.5]. As we know, the existing literature of approximating convergence for several mappings in CAT(0) spaces restricts to explicit iteration schemes. Theorems 3.13.3 extend and develop some existing results such as [7, Theorems 3.4 and 3.5] and [11, Theorems 3.2-3.4] from explicit Mann iteration schemes to implicit Mann iteration processes with perturbations.

We prove another strong convergence theorem which is different from Theorem 3.3.

Theorem 3.4 Let $K$ be a compact and convex subset of a complete $C A T(0)$ space $X$, and $\Gamma=\left\{T(t): t \in \mathbb{R}^{+}\right\}$be a nonexpansive semigroup on $K$. Let $\left\{u_{n}\right\}$ be a bounded sequence in $K,\left\{\alpha_{n}\right\} \subset(0,1]$ and $\left\{\theta_{n}\right\} \subset[0,1]$ be given sequences. Then the sequence $\left\{x_{n}\right\}$ generated by scheme (1.3) is well defined. If

$$
\lim _{n \rightarrow \infty} t_{n}=\lim _{n \rightarrow \infty} \frac{\alpha_{n}+\theta_{n}}{t_{n}}=0
$$

and $\sum_{n=1}^{\infty} \theta_{n}<+\infty$, then $\left\{x_{n}\right\}$ converges strongly to a common fixed point $x^{*}$ of $\Gamma$.

Proof Following the proof details of the main result of [2], we know that $F(\Gamma)$ in complete CAT(0) spaces is nonempty (see [2, 7]). From Lemma 3.1, we know that $\left\{x_{n}\right\}$ generated by (1.3) is well defined.

Claim 1: If $\left\{r_{n}\right\}$ is a sequence of nonnegative real numbers such that $\lim _{n \rightarrow \infty} r_{n}=0$, then

$$
\lim _{n \rightarrow \infty} \sup _{x \in K} d\left(T\left(r_{n}\right) x, T(0) x\right)=0 .
$$

Assume for the contrary that (3.5) does not hold. There exist a subsequence $\left\{r_{n_{k}}\right\} \subset\left\{r_{n}\right\}$, a sequence $\left\{y_{k}\right\} \subset K$ and an $\eta>0$ such that for all $k \in \mathbb{N}$,

$$
d\left(T\left(r_{n_{k}}\right) y_{k}, T(0) y_{k}\right) \geq \eta
$$

Since $K$ is compact, there exists a convergent subsequence of $\left\{y_{k}\right\}$. Without loss of generality, we assume that $y_{k} \rightarrow y$ as $k \rightarrow \infty$. Obviously, $y \in K$ and so

$$
\begin{aligned}
0 & <\eta \\
& \leq \limsup _{k \rightarrow \infty} d\left(T\left(r_{n_{k}}\right) y_{k}, T(0) y_{k}\right) \\
& \leq \limsup _{k \rightarrow \infty}\left[d\left(T\left(r_{n_{k}}\right) y_{k}, T\left(r_{n_{k}}\right) y\right)+d\left(T\left(r_{n_{k}}\right) y, T(0) y\right)+d\left(T(0) y, T(0) y_{k}\right)\right] \\
& \leq \limsup _{k \rightarrow \infty}\left[2 d\left(y_{k}, y\right)+d\left(T\left(r_{n_{k}}\right) y, T(0) y\right)\right]=0,
\end{aligned}
$$

which is a contradiction. Formula (3.5) follows readily.

Claim 2: $\lim _{n \rightarrow \infty} d\left(x_{n}, T(t) x_{n}\right)=0$. Since $K$ is a compact and convex subset of $X$, there exists a subsequence $\left\{x_{n_{j}}\right\} \subset\left\{x_{n}\right\}$ such that $x_{n_{j}} \rightarrow x^{*}$ as $j \rightarrow \infty$. It follows from (1.3) and 
Lemma 2.1 that

$$
\begin{aligned}
d\left(x_{n}, T\left(t_{n}\right) x_{n}\right) & =d\left(\alpha_{n} x_{n-1} \oplus\left(1-\alpha_{n}\right)\left(\left(1-\theta_{n}\right) T\left(t_{n}\right) x_{n} \oplus \theta_{n} u_{n}\right), T\left(t_{n}\right) x_{n}\right) \\
& \leq \alpha_{n} d\left(x_{n-1}, T\left(t_{n}\right) x_{n}\right)+\left(1-\alpha_{n}\right) \theta_{n} d\left(u_{n}, T\left(t_{n}\right) x_{n}\right) \\
& \leq\left[\alpha_{n}+\left(1-\alpha_{n}\right) \theta_{n}\right] d\left(x_{n}, T\left(t_{n}\right) x_{n}\right)+\alpha_{n} d\left(x_{n-1}, x_{n}\right)+\left(1-\alpha_{n}\right) \theta_{n} d\left(u_{n}, x_{n}\right) .
\end{aligned}
$$

Thus, we have

$$
d\left(x_{n}, T\left(t_{n}\right) x_{n}\right) \leq \frac{\alpha_{n}+\theta_{n}}{\left(1-\alpha_{n}\right)\left(1-\theta_{n}\right)}\left[d\left(x_{n-1}, x_{n}\right)+d\left(u_{n}, x_{n}\right)\right] .
$$

For any given $x \in X$, let $M_{1}=\sup \left\{d\left(x_{n}, x\right): n \in \mathbb{N}\right\}$ and $M_{2}=\sup \left\{d\left(u_{n}, x\right): n \in \mathbb{N}\right\}$. Since $K$ is compact and $\left\{u_{n}\right\}$ is bounded, it follows that $M_{1}<+\infty$ and $M_{2}<+\infty$. Also, we know that $\alpha_{n} \leq 1 / 2$ and $\theta_{n} \leq 1 / 2$ for sufficiently large $n \in \mathbb{N}$, because $\lim _{n \rightarrow \infty} \alpha_{n}=0$ and $\lim _{n \rightarrow \infty} \theta_{n}=0$. Consequently,

$$
\begin{aligned}
d\left(x_{n}, T\left(t_{n}\right) x_{n}\right) & \leq 4\left(\alpha_{n}+\theta_{n}\right)\left[d\left(x_{n-1}, x\right)+2 d\left(x_{n}, x\right)+d\left(u_{n}, x\right)\right] \\
& \leq 12\left(M_{1}+M_{2}\right)\left(\alpha_{n}+\theta_{n}\right) \rightarrow 0 .
\end{aligned}
$$

Hence, it follows from (3.5) that

$$
\begin{aligned}
\limsup _{n \rightarrow \infty} d\left(T(0) x_{n}, x_{n}\right) & \leq \limsup _{n \rightarrow \infty}\left[d\left(T(0) x_{n}, T\left(t_{n}\right) x_{n}\right)+d\left(T\left(t_{n}\right) x_{n}, x_{n}\right)\right] \\
& \leq \lim _{n \rightarrow \infty} \sup _{x \in K} d\left(T(0) x, T\left(t_{n}\right) x\right)+\limsup _{n \rightarrow \infty} d\left(x_{n}, T\left(t_{n}\right) x_{n}\right)=0 .
\end{aligned}
$$

For any given $t>0$, from (3.6) we know that

$$
\begin{aligned}
d\left(T(0) x_{n}, T(t) x_{n}\right) & \leq \sum_{k=0}^{\left[t / t_{n}\right]-1} d\left(T\left(k t_{n}\right) x_{n}, T\left((k+1) t_{n}\right) x_{n}\right)+d\left(T\left(\left[t / t_{n}\right] t_{n}\right) x_{n}, T(t) x_{n}\right) \\
& \leq\left[t / t_{n}\right] d\left(x_{n}, T\left(t_{n}\right) x_{n}\right)+d\left(T\left(t-\left[t / t_{n}\right] t_{n}\right) x_{n}, x_{n}\right) \\
& \leq 12\left(M_{1}+M_{2}\right) t \frac{\alpha_{n}+\theta_{n}}{t_{n}}+\max \left\{d\left(T(s) x_{n}, x_{n}\right): 0 \leq s \leq t_{n}\right\} \\
& =12\left(M_{1}+M_{2}\right) t \frac{\alpha_{n}+\theta_{n}}{t_{n}}+d\left(T\left(s_{n}\right) x_{n}, x_{n}\right) \quad\left(\text { say } s_{n} \in\left[0, t_{n}\right]\right) \\
& \leq 12\left(M_{1}+M_{2}\right) t \frac{\alpha_{n}+\theta_{n}}{t_{n}}+d\left(T\left(s_{n}\right) x_{n}, T(0) x_{n}\right)+d\left(T(0) x_{n}, x_{n}\right) \\
& \leq 12\left(M_{1}+M_{2}\right) t \frac{\alpha_{n}+\theta_{n}}{t_{n}}+d\left(T(0) x_{n}, x_{n}\right)+\sup _{x \in K} d\left(T\left(s_{n}\right) x, T(0) x\right)
\end{aligned}
$$

where $\left[t / t_{n}\right]$ is the integer part of $t / t_{n}$. Since $\lim _{n \rightarrow \infty} \frac{\alpha_{n}+\theta_{n}}{t_{n}}=0$, it follows from (3.5) and (3.7) that

$$
\lim _{n \rightarrow \infty} d\left(x_{n}, T(t) x_{n}\right)=0
$$


Therefore, from the above equality, we know that $x^{*} \in F(\Gamma)$. From (3.3), Lemma 2.5 yields that $\lim _{n \rightarrow \infty} d\left(x_{n}, x^{*}\right)$ exists and thus $\left\{x_{n}\right\}$ converges strongly to $x^{*}$ as $n \rightarrow \infty$. This completes the proof.

Remark 3.2 The main results presented in this paper can be immediately applied to any $\mathrm{CAT}(k)$ space with $k \leq 0$, because any $\operatorname{CAT}(k)$ space is a $\operatorname{CAT}\left(k^{\prime}\right)$ space for any $k^{\prime}>k$ (see $[4,7])$.

If $X$ is a Banach space, from Theorem 3.4, we have the following corollary.

Corollary 3.1 Let $K$ be a compact and convex subset of a Banach space $X$, and $\Gamma=\{T(t)$ : $\left.t \in \mathbb{R}^{+}\right\}$be a nonexpansive semigroup on $K$. Let $\left\{u_{n}\right\}$ be a bounded sequence in $K,\left\{\alpha_{n}\right\} \subset$ $(0,1]$ and $\left\{\theta_{n}\right\} \subset[0,1]$ be given sequences. Then the sequence $\left\{x_{n}\right\}$ generated by

$$
x_{0} \in K, \quad x_{n}=\alpha_{n} x_{n-1}+\left(1-\alpha_{n}\right)\left(\left(1-\theta_{n}\right) T\left(t_{n}\right) x_{n}+\theta_{n} u_{n}\right), \quad \forall n \geq 1
$$

is well defined. If

$$
\lim _{n \rightarrow \infty} t_{n}=\lim _{n \rightarrow \infty} \frac{\alpha_{n}+\theta_{n}}{t_{n}}=0
$$

and $\sum_{n=1}^{\infty} \theta_{n}<+\infty$, then $\left\{x_{n}\right\}$ converges strongly to a common fixed point $x^{*}$ of $\Gamma$.

Remark 3.3 When $\theta_{n} \equiv 0$, Corollary 3.1 reduces to [20, Theorem 2.3]. Therefore, Theorem 3.4 and Corollary 3.1 extend [20, Theorem 2.3] from implicit Mann iteration processes to implicit Mann iteration processes with bounded perturbations.

\section{Competing interests}

The authors declare that they have no competing interests.

\section{Authors' contributions}

All authors contributed equally and significantly in writing this paper. All authors read and approved the final manuscript.

\section{Author details}

${ }^{1}$ Department of Mathematics, Sichuan University, Chengdu, Sichuan 610064, P.R. China. ${ }^{2}$ Department of Logistics and Maritime Studies, Faculty of Business, Hong Kong Polytechnic University, Hong Kong, P.R. China.

\section{Acknowledgements}

This work was supported by the National Natural Science Foundation of China $(11026063,11171237,11101069)$. This work was also supported by a Hong Kong Polytechnic University Postdoctoral Fellowship (Number G-YX4N) and an Internal Competitive Research Grant (Number A-PL05).

Received: 27 March 2012 Accepted: 22 August 2012 Published: 11 September 2012

\section{References}

1. Browder, FE: Nonexpansive nonlinear operators in a Banach space. Proc. Natl. Acad. Sci. USA 54, 1041-1044 (1965)

2. DeMarr, R: Common fixed points for commuting contraction mappings. Pac. J. Math. 13, 1139-1141 (1963)

3. Lim, TC: A fixed point theorem for families of nonexpansive mappings. Pac. J. Math. 53, 487-493 (1974)

4. Bridson, M, Haefliger, A: Metric Spaces of Non-Positive Curvature. Springer, New York (1999)

5. Kirk, WA: A fixed point theorem in CAT(0) spaces and R-trees. Fixed Point Theory Appl. 4, 309-316 (2004)

6. Ćirić, L: Common fixed point theorems for a family of non-self mappings in convex metric spaces. Nonlinear Anal. 71(5-6), 1662-1669 (2009)

7. Cho, YJ, Ćirić, L, Wang, SH: Convergence theorems for nonexpansive semigroups in CAT(0) spaces. Nonlinear Anal. 74, 6050-6059 (2011)

8. Dhompongsa, S, Kaewkhao, A, Panyanak, B: Lim's theorems for multivalued mappings in CAT(0) spaces. J. Math. Anal. Appl. 312, 478-487 (2005) 
9. Dhompongsa, S, Kirk, WA, Sims, B: Fixed points of uniformly Lipschitzian mappings. Nonlinear Anal. 65, 762-772 (2006)

10. Dhompongsa, S, Kirk, WA, Panyanak, B: Nonexpansive set-valued mappings in metric and Banach spaces. J. Nonlinear Convex Anal. 8, 35-45 (2007)

11. Dhompongsa, S, Panyanak, B: On $\triangle$-convergence theorems in CAT(0) spaces. Comput. Math. Appl. 56, 2572-2579 (2008)

12. Khan, AR, Khamsi, MA, Fukhar-ud-din, $\mathrm{H}$ : Strong convergence of a general iteration scheme in CAT(0) spaces. Nonlinear Anal. 74, 783-791 (2011)

13. Kirk, WA, Panyanak, B: A concept of convergence in geodesic spaces. Nonlinear Anal. 68, 3689-3696 (2008)

14. Laowang, W, Panyanak, B: Strong and $\triangle$ convergence theorems for multivalued mappings in CAT(0) spaces. Fixed Point Theory Appl. 2009, Art. ID 730132 (2009)

15. Laowang, W, Panyanak, B: Approximation fixed points of nonexpansive nonself mappings in CAT(0) spaces. Fixed Point Theory Appl. 2010, Art. ID 367274 (2010)

16. Leustean, L: A quadratic rage of asymptotic regularity for CAT(0) spaces. J. Math. Anal. Appl. 325, 386-399 (2007)

17. Nanjaras, B, Panyanaka, B, Phuengrattana, W: Fixed point theorems and convergence theorems for Suzuki-generalized nonexpansive mappings in CAT(0) spaces. Nonlinear Anal. Hybrid Syst. 4, 25-31 (2010)

18. Saejung, S: Halpern's iteration in CAT(0) spaces. Fixed Point Theory Appl. 2010, Art. ID 471781 (2010)

19. Razani, A, Salahifard, H: Invariant approximation for CAT(0) spaces. Nonlinear Anal. 72, 2421-2425 (2010)

20. Thong, DV: An implicit iteration process for nonexpansive semigroups. Nonlinear Anal. 74, 6116-6120 (2011)

21. Chidume, CE, Shahzad, N: Strong convergence of an implicit iteration process for a finite family of nonexpansive mappings. Nonlinear Anal. 62, 1149-1156 (2005)

22. Li, XS, Huang, NJ, Kim, JK: General viscosity approximation methods for common fixed points of nonexpansive semigroups in Hilbert spaces. Fixed Point Theory Appl. 2011, Art. ID 783502 (2011)

23. Qin, XL, Cho, SY: Implicit iterative algorithms for treating strongly continuous semigroups of Lipschitz pseudocontractions. Appl. Math. Lett. 23, 1252-1255 (2010)

24. Xu, HK, Ori, RG: An implicit iteration process for nonexpansive mappings. Numer. Funct. Anal. Optim. 22(5-6), 767-773 (2001)

25. Buong, N: Hybrid Ishikawa iterative methods for a nonexpansive semigroup in Hilbert space. Comput. Math. Appl. 61, 2546-2554 (2011)

26. Tan, KK, Xu, HK: Approximating fixed points of nonexpansive mappings by the Ishikawa iteration process. J. Math. Anal. Appl. 178, 301-308 (1993)

27. Lim, TC: Remarks on some fixed point theorems. Proc. Am. Math. Soc. 60, 179-182 (1976)

28. Suzuki, T: Strong convergence theorems for infinite families of nonexpansive mappings in general Banach spaces Fixed Point Theory Appl. 1, 103-123 (2005)

doi:10.1186/1687-1812-2012-145

Cite this article as: $\mathrm{Li}$ and Yip: Implicit Mann approximation with perturbations for nonexpansive semigroups in CAT(0) spaces. Fixed Point Theory and Applications 2012 2012:145.

\section{Submit your manuscript to a SpringerOpen ${ }^{\circ}$ journal and benefit from:}

- Convenient online submission

Rigorous peer review

- Immediate publication on acceptance

- Open access: articles freely available online

- High visibility within the field

- Retaining the copyright to your article 